\title{
Outcomes of very low birth weight infants born by vaginal delivery versus cesarean section
}

\author{
DARJAN KARDUM ${ }^{1,2}$, BORIS FILIPOVIĆ GRČIĆ ${ }^{3,4}$, ANDRIJANA MULLER ${ }^{1,5}$, SANDRO DESSARDO ${ }^{6,7}$ \\ 1 Neonatal Intensive Care Unit, Department of Pediatrics, University Hospital Osijek, Osijek, Croatia \\ 2 School of Medicine, University J. J. Strossmayer Osijek, Osijek, Croatia \\ 3 Neonatal Intensive Care Unit, Department of Pediatrics, University Hospital Zagreb, Zagreb, Croatia \\ 4 School of Medicine, University of Zagreb, Zagreb, Croatia \\ 5 Department of Gynecology and Obstetrics, University Hospital Osijek, Osijek, Croatia \\ 6 Neonatal and Pediatric Intensive Care Unit, Department of Pediatrics, University Hospital Rijeka, Rijeka, Croatia \\ 7 School of Medicine, University of Rijeka, Rijeka, Croatia
}

Corresponding author:

Darjan Kardum

Neonatal Intensive Care Unit, Department of Pediatrics

University Hospital Osijek

J. Huttlera 4, 31000 Osijek

School of Medicine

University J. J. Strossmayer Osijek

University Department of Pediatrics

Cara Hadrijana 10/E, 31000 Osijek

Phone: 0038531512288

E-mail:darjankardum@gmail.com

\section{ABSTRACT}

The optimal mode of delivery for very low birth weight (VLBW) infants remains controversial. Despite lacking evidence of benefits regarding neonatal outcomes, cesarean section delivery is becoming more prevalent, particularly in early gestational ages. In our retrospective, multicentr study data were collected for very low birth weight infants born in two Croatian perinatal regions in a 3 - year period (2014. - 2016.). The final cohort consisted of 255 very low birth weight infants. The rate of delivery via cesarean section was $74.1 \%(189 / 255)$ and is one of the highest reported in the literature so far. Infants born vaginally were born at an lower gestational age, had lower 1- and 5-minute Apgar scores, lower birth weights, and prognosis as expressed by higher Clinical risk index for babies (CRIB) scores and were more often born following chorioamnionitis and had higher mortality rate until 7 days of hospitalization. Univariate logistic regression analysis showed that cesarean section reduced the risk of death before 7 days of life (OR 0.34 95\% CI 0.182-0.667). This significance was lost after multivariate analysis. In infants surviving after 7 days of hospitalization, rates of short-term neonatal morbidity (severe intracranial hemorrhage, cystic periventricular leukomalacia (cPVL), late-onset sepsis, necrotizing enterocolitis, kidney injury and retinopathy of prematurity requiring interventions) were not significant when comparing infants born vaginally and those born following cesarean section.

Key words: cesarean section, very low birth weight infants, vaginal delivery

\section{INTRODUCTION}

Preterm birth remains the major cause of mortality and long-term morbidity in infancy despite advances in perinatal care. (1) Cesarean section delivery has been proposed as

an obstetric strategy to improve neonatal outcome in situations in which preterm delivery is regarded as necessary or inevitable. (2) Several studies aimed to determine whether cesarean section delivery is beneficiary to outcomes of premature infants, but there were no statistically significant differences were found. (3) Despite lacking evidence of benefits regarding neonatal outcomes, cesarean section delivery is becoming more prevalent, particularly in early gestational ages. $(4,5)$ In the discussion regarding obstetric interventions to reduce neonatal morbidity, maternal outcomes must be considered.

A study by Stohl et al. (6) found no benefit in very low birth weight (VLBW) singleton infants but rather found higher maternal morbidity with cesarean delivery. Hyster- otomy at an early gestational age is associated with an increased risk for short-term maternal complications such as bladder injury or extension to the uterine artery and often requires a vertical uterine incision with its associated increased risk of uterine rupture in subsequent pregnancies. (2) Controversies regarding the best mode of delivery of preterm infants are bound to persist until large randomized studies are published. It is doubtful that such studies could be done due to ethical issues. (7) Our study analyzes very low birth weight infants and compares various outcomes between those who were delivered vaginally or abdominally.

\section{MATERIALS AND METHODS}

All liveborn infants in two Croatian perinatal regions were eligible for inclusion in the study if they met the following four criteria: they were born between January 1, 2014 and December 31, 2016. and their gestational age at birth was $\geq 220 / 7$ weeks, their birth weight was $<1500 \mathrm{~g}$ and they were born in delivery wards in the regions (2 level III neonatal units, 2 level II neonatal units and 5 level I neonatal wards). 255 infants met the eligibility criteria. Enrolled infants were actively followed from birth to hospital discharge.

Gestational age (GA) was determined in the following order: (1) an obstetric ex- 
amination with ultrasonography during the first trimester, (2) obstetric history taking into account the last menstrual period, and (3) a postnatal physical examination of the neonate. Antenatal steroid use was defined as administration of dexamethasone to accelerate fetal maturity with at least 1 dose. Chorioamnionitis was defined based on histological findings and where histology was not done, the diagnosis was based on previously described criteria. (8) Maternal hypertension was defined based on previous studies. (9) Delivery room resuscitation was defined as any endotracheal intubation and/or chest compression and/ or fluid boluses and/or any epinephrine administration in the delivery room. Clinical Risk for Index Babies (CRIB score) was calculated based on author's instructions. (10)

Infants were diagnosed with late-onset sepsis if they had positive blood cultures for either bacteria or fungi after 7 days of life. Severe intracranial hemorrhage (ICH) was classified as intraventricular hemorrhage (IVH) grade III-IV as classified by Papille et al. (11) Necrotizing enterocolitis (NEC) was diagnosed as per Bell's stage $\geq 3 \mathrm{~A}$ classification. (12) Kidney failure was diagnosed if the infant met the neonatal RIFLE criteria for injury or failure. (13) Periventricular leukomalacia was diagnosed with $\geq$ grade II classified by de Vries et al. (14) Bronchopulmonary dysplasia (BPD) was defined as any moderate or severe bronchopulmonary dysplasia as classified by Jobe et al. (15) Retinopathy of prematurity (ROP) was defined as any ROP requiring intervention (laser photocoagulation or intravitreal application of anti - vascular endothelial growth factor (VEGF) drugs).

This study was approved by the Ethics Committees of all participating institutions. All procedures were performed in accordance with the Declaration of Helsinki.

Data were described using descriptive statistical methods. The two-tailed Fisher's exact test was used to test for associations between the categorical variables. The Mann - Whitney test was used to compare differences between two independent groups. Logistic regression was used to describe data and to explain the relationship between the dependent binary variable and one or more predicted independent variables. $\mathrm{P}<0.05$ was defined as indicative of statistical significance. The statistical analysis was performed using MedCalc Statistical Software version 18.2.1 (MedCalc Software bvba, Ostend, Belgium; http://www.medcalc.org; 2018).

\section{RESULTS}

The final cohort consisted of 255 very low birth weight infants. $25.7 \%$ (66/255) were born vaginally and $74.1 \%(189 / 255)$ were born via cesarean section.

Compared with infants born via cesarean section (table 1), infants born vaginally were born at an lower gestational age (median $27(24-29)$ vs. 28 (26 - 30), p $<0.001$ ), a worse postnatal condition, as expressed by the 1 - minute Apgar score (median $4(2-7)$ vs $6(4-9), \mathrm{p}<0,001)$, 5 - minute Apgar score (median $6(4-7)$ vs $7(5-10), p<0,001)$, had lower birth weight (median $885(700-1200)$ g vs. 1040 $(808$ - 1292) g, $\mathrm{p}=0,03)$,

a worse prognosis as expressed by higher CRIB scores (median 5 (1-9) vs 1 (1-7), p $=0.002)$ and were more often born following chorioamnionitis $(59.7 \%$ vs $43.4 \%, \mathrm{p}=$ 0.02).

Compared with infants born vaginally, mothers of infants born via cesarean section were more often administered prenatal corticosteroids $(63.5 \%$ vs $26.9 \%$, p < 0.001 ) and were more often born to mothers with hypertension $(26.5 \%$ vs $1.5 \%, \mathrm{p}<$ $0.001)$. Death before 7 days of hospitalization was higher in infants born vaginally ( $33.3 \%$ vs $14.8 \%, p=0.002)$.The results of the univariate logistic regression (table 2) showed that risk factors for death before 7 days of hospitalization were gestational age (OR 0.57 95\% CI 0.482-0.674), birth weight (OR 0.99 95\% CI 0.992-0.996), lower 1 minute (OR $0.6095 \%$ CI 0.509-0.699), and 5 - minute Apgar score (OR 0.52 95\% CI 0.434 - 0.624), lower initial pH (OR 0.99 95\% CI 0.988-0.995) and higher CRIB scores (OR 1.521 95\% CI 1.355-1.688). In the univariate logistic regression, the only parameter that reduced the risk of death before 7 days of life was the cesarean section (OR 0.34 95\% CI 0.182-0.667).

In the multivariate regression analysis (table 3) as a model, we analyzed predictors that were significant in the univariate regression analysis (gestational age, birth weight, 1 - minute and 5 - minute Apgar score, initial $\mathrm{pH}, \mathrm{CRIB}$ scores and mode of delivery). Following the multivariant regression analysis, three independent predictors gave a unique statistical contribution to the model. It is, as a whole, statistically significant, $\chi 2=161,27, \mathrm{P}<0,001$, which shows it can differentiate subjects according to outcomes. It explains between 47,40\% (Cox \& Snell) and 67,08\% (Negelkerke) variance of negative outcome and accurately classifies $85,66 \%$ of subjects. Mode of delivery became insignificant and the most significant risk factor for death until the 7th day of life was a higher initial neonatal risk as expressed by CRIB score (OR 1.62 95\% CI 1.322 - 1.982).

Regarding outcomes in VLBW infants surviving $>7$ days of hospitalization (table 4), infants born vaginally required delivery room resuscitation more often $(34,1 \%$ vs $17,4 \%, p=0,02)$, had hemodynamically significant Patent ductus arteriosus (PDA) ( $46,9 \%$ vs $27,8 \%, \mathrm{p}=0.04$ ) and were more often mechanically ventilated during hospitalization $(79,5 \%$ vs $57,8 \%, \mathrm{p}=0,008)$. Rates of bronchopulmonary dysplasia, necrotizing enterocolitis, retinopathy of prematurity requiring treatment, kidney failure, severe intracranial hemorrhage and periventricular leukomalacia did not vary between infants born vaginally and via cesarean section.

\section{DISCUSSION}

The optimal mode of delivery in preterm and very low birth weight neonates remains unclear due to lack of large prospective population-based cohort studies. The positive benefits of cesarean section compared to vaginal delivery in this group of infants are less stress of labor and avoidance of potential trauma of passage through the birth canal. (2)

The proposed benefits in regard to outcomes are reserved for the most immature infants delivered at 22 to 25 weeks of gestation. (16) No clear evidence for benefit of cesarean section in children of higher gestation is found. (16-21) Notwithstanding, the rates of delivery in very low birth weight infants via cesarean section are increasing dramatically. (21)

In our cohort cesarean section is the mode of delivery for $74.1 \%$ of VLBW infants and, is among the highest reported. (22) VLBW infants born vaginally were born at a lower gestational age. This is consistent with previous studies which found that the rate of cesarean deliveries increased with gestational age. (23) This may reflect obstetricians' decisions to avoid hysterotomy in light of few proposed benefits to the infant and intent to reduce the risk of short-term maternal complications. (2) The rate of maternal hypertension in the group of infants born via cesarean section was $26.5 \%$. This could be influenced by finding that maternal hypertension dictates immediate delivery. (23)

Rates of death until 7 days of hospitalization were higher in infants born vaginally, and several factors in the univariate analysis were determined to impact such results (gestational age, birth weight, lower 
Table 1. Comparison of the two groups of VLBW infants

\begin{tabular}{llll}
\hline & Vaginal delivery $(\mathbf{n}=\mathbf{6 6})$ & Cesarean section $(\mathbf{n}=\mathbf{1 8 9})$ & P value \\
\hline $\begin{array}{l}\text { Gestational age (completed weeks of } \\
\text { gestation) [Median(IQR)] }\end{array}$ & $27(24-29)$ & $28(26-30)$ & $<0,001^{*}$ \\
\hline Birth weight $(\mathrm{g})[$ Median(IQR)] & $885(700-1200)$ & $1040(808-1292)$ & $0,03^{*}$ \\
\hline 1 - minute Apgar score [Median(IQR)] & $4(2-7)$ & $6(4-9)$ & $<0,001^{*}$ \\
\hline 5 - minute Apgar score [Median(IQR)] & $6(4-7)$ & $7(5-10)$ & $<0,001^{*}$ \\
\hline pH on admission [Median(IQR)] & $7,3(7,1-7,3)$ & $7,3(7,2-7,3)$ & $0,08^{*}$ \\
\hline BE on admission [Median(IQR)] & $-11(-29$ to -3,5) & $-6,7(-18,7$ to -3$)$ & $0,20^{*}$ \\
\hline CRIB score [Median(IQR)] & $5(1-9)$ & $1(1-7)$ & $0,002^{*}$ \\
\hline Sex, M:F, $\%$ M) & $36: 31(53,7)$ & $94: 95(49,7)$ & $0,67 \dagger$ \\
\hline Prenatal corticosteroids, any [n(\%)] & $18(26,9)$ & $120(63,5)$ & $<0,001 \dagger$ \\
\hline Chorioamnionitis [n(\%)] & $40(59,7)$ & $82(43,4)$ & $0,02 \dagger$ \\
\hline Multiparity [n(\%)] & $10(14,9)$ & $51(27)$ & $0,05 \dagger$ \\
\hline Maternal hypertension [n(\%)] & $1(1,5)$ & $50(26,5)$ & $<0,001 \dagger$ \\
\hline Died before 7 days [n(\%)] & & $161(85,2)$ & $0,002 \dagger$ \\
\hline No & $44(66,7)$ & $28(14,8)$ & \\
\hline Yes & $22(33,3)$ & & \\
\hline
\end{tabular}

${ }^{*}$ Mann Whitney U test; †Fisher's exact test.

$\mathrm{BE}$, base excess; CRIB, clinical risk index for babies;IQR, interquartile range; VLBW, very low birth weight.

Table 2. Univariate logistic regression analysis of parameters impacting death before 7 days of life

\begin{tabular}{llll}
\hline Parameters & Odds ratio & $\mathbf{9 5}$ CI & P value \\
\hline Gestational age & 0,57 & $0,482-0,674$ & $<0,001$ \\
\hline Birth weight & 0,99 & $0,992-0,996$ & $<0,001$ \\
\hline 1 - minute Apgar score & 0,60 & $0,509-0,699$ & $<0,001$ \\
\hline 1 - minute Apgar score & 0,52 & $0,434-0,624$ & $<0,001$ \\
\hline pH on admission & 0,99 & $0,994-0,995$ & 0,001 \\
\hline BE on admission & 0,99 & $0,988-1,009$ & 0,85 \\
\hline CRIB score & 1,512 & $1,355-1,688$ & $<0,001$ \\
\hline Sex & 1,57 & $0,84-2,95$ & 0,16 \\
\hline Prenatal corticosteroids & 0,55 & $0,297-1,038$ & 0,06 \\
\hline Chorioamnionitis & 0,91 & $0,491-1,695$ & 0,77 \\
\hline Multiparity & 0,75 & $0,352-1,617$ & 0,49 \\
\hline Maternal hypertension & 0,38 & $0,144-1,023$ & 0,06 \\
\hline
\end{tabular}

$\mathrm{BE}$, base excess; CRIB, clinical risk index for babies.

Table 3. Multivariate regression analysis of the risk parameters significantly impacting death before 7 days of life.

\begin{tabular}{lllllll}
\hline Parameters & $\boldsymbol{\beta}$ & SEM & Wald & P value & Odds ratio & 95\% CI \\
\hline Birth weight & 0,003 & 0,001 & 3,87 & 0,04 & 1,003 & $1,001-1,005$ \\
\hline $\begin{array}{l}5 \text { - minute Apgar } \\
\text { score }\end{array}$ & $-0,482$ & 0,12 & 17,33 & $<0,001$ & 0,62 & $0,492-0,775$ \\
\hline CRIB score & 0,481 & 0,10 & 21,76 & $<0,001$ & 1,62 & $1,322-1,982$ \\
\hline Constant & $-4,22$ & 1,77 & 5,68 & 0,02 & & \\
\hline
\end{tabular}

CI, confidence interval; CRIB, clinical risk index for babies. 
Table 4. Comparison of outcomes in infants surviving $>7$ days of hospitalization

\begin{tabular}{|c|c|c|c|}
\hline \multirow{2}{*}{ Outcome } & \multicolumn{2}{|l|}{ No (\%) VLBW infants } & \multirow{2}{*}{-P value ${ }^{\star}$} \\
\hline & Vaginal delivery $(n=44)$ & Cesarean section $(n=161)$ & \\
\hline Delivery room resuscitation & $15 / 44(34,1)$ & $28 / 161(17,4)$ & 0,02 \\
\hline Delivery room CPAP & $3 / 44(6,8)$ & 21/161 (13) & 0,30 \\
\hline RDS requiring surfactant & $37 / 44(84,1)$ & $123 / 161(76,4)$ & 0,31 \\
\hline Mehanical ventilation, any & $35 / 44(79,5)$ & $93 / 161(57,8)$ & 0,008 \\
\hline Bronchopulmonary dysplasia & $24 / 37(64,9)$ & $76 / 155(49)$ & 0,10 \\
\hline Late onset sepsis & $19 / 30(63,3)$ & $59 / 116(50,9)$ & 0,31 \\
\hline $\begin{array}{l}\text { Patent ductus arteriosus, haemodi- } \\
\text { namicaly significant }\end{array}$ & $15 / 32(46,9)$ & $32 / 115(27,8)$ & 0,04 \\
\hline Necrotising enterocolitis & $8 / 14(57,1)$ & $16 / 44(36,4)$ & 0,22 \\
\hline $\begin{array}{l}\text { Retinopathy of prematurity requir- } \\
\text { ing treatment }\end{array}$ & $11(16,4)$ & $20(10,6)$ & 0,27 \\
\hline Kidney failure & $9 / 44(20,5)$ & $17 / 161(10,6)$ & 0,12 \\
\hline Severe intracranial hemorrhage & $11 / 44(25)$ & 29/161 (18) & 0,29 \\
\hline Periventricular leucomalacia & $5 / 44(11,4)$ & $15 / 161(9,3)$ & 0,77 \\
\hline
\end{tabular}

* Fisher's exact test

CPAP, continuous positive airway pressure; RDS, respiratory distress syndrome; VLBW, very low birth weight.

1 - minute and 5 - minute Apgar, lower initial $\mathrm{pH}$, and higher CRIB scores). In the univariate logistic regression, the only parameter that reduced the risk of death before 7 days of life was the cesarean section (OR 0.34 95\% CI 0.182-0.667) but multivariate regression analysis of parameters influencing outcomes revealed no impact of mode of delivery on death until 7 days. This finding is consistent with previous studies which found no association between mode of delivery and VLBW infant mortality rates. (24)

In our cohort of infants surviving $>7$ days, cesarean section delivery was associated with less need for mechanical ventilation $(57,8 \% 79.5 \%, p=0,008)$ and need for delivery room resuscitation $(17,4 \%$ vs $34.1 \%$, $\mathrm{p}=0.02$ ). This, however, did not influence rates of moderate and severe BPD in infants born vaginally versus those delivered via cesarean section. This finding is consistent with previous studies. (23) A similar result was found when observing other outcomes in infants surviving $>7$ days. Rates of severe intracranial hemorrhage, cPVL, late-onset sepsis, necrotizing enter- ocolitis, kidney injury and retinopathy of prematurity requiring interventions were not significantly increased among infants born vaginally and those delivered via cesarean section.

The optimal mode of delivery for VLBW infants remains a controversial one, with several observational studies producing conflicting results. $(18,23-26)$

The main finding in our study is that delivery mode did not affect neonatal mortality within the first seven days of life and did not influence preterm morbidity in infants surviving $>7$ days of life. This finding is supported by other population studies in Australia (27) and the USA. (26) These finding must be taken into account when considering a cesarean section as the optimal mode of delivery in VLBW infants, especially in regards to known increased maternal morbidity following cesarean section. Based on current evidence, cesarean section cannot be recommended as the routine mode of delivery, except in the presence of clear fetal or maternal indications (i.e. preeclampsia).

There are several limitations to our study.
In infants born via cesarean section, we did not take into account whether the procedure was elective one, or if it was urgent following having attempted vaginal delivery. In infants born vaginally, we did not differentiate between those born following vertex or breech presentation. Since randomized trials are unfeasible, prospective studies are the only way for better identifying very low birth weight infants who could benefit from either mode of delivery.

\section{CONCLUSION}

Current evidence does not support preferring cesarean section as an optimal mode of delivery in very low birth weight infants. Despite this, rates of cesarean section in this population of infants are rising, as reflected in our study. Our data are consistent with similar studies which show that mode of delivery does not influence mortality or morbidity in very low birth weight infants.

\section{REFERENCES}

1. Stockman J. The contribution of preterm birth to infant mortality rates in the United States. Yearbook of Pediatrics 2008;2008:38890.

2. Wylie BJ, Davidson LL, Batra M, Reed SD. Method of delivery and neonatal outcome in very low-birthweight vertex-presenting fetuses. Am J Obstet Gyneco 2008;198(6) : 640.e1-7.

3. Grant A, Glazener CMA. Elective cesarean section versus expectant management for delivery of the small baby. Cochrane Data- 
base Syst Rev 2001;2:CD000078.

4. Redman ME, Gonik B. Cesarean delivery rates at the threshold of viability. Am J Obstet Gynecol 2002;187(4):873-6.

5. Bottoms S, Paul R, Iams J, Mercer B, Thom E, Roberts J, et al. Obstetric determinants of neonatal survival: Influence of willingness to perform cesarean delivery on survival of extremely low-birth-weight infants. Am J Obstet Gynecol 1997;176(5):960-6.

6. Stohl HE, Szymanski LM, Althaus J. Vaginal breech delivery in very low birth weight (VLBW) neonates: experience of a single center. J Perinat Med 2011Jan;39(4):379-83.

7. Görbe E, Chasen S, Harmath A, Patkós P, Papp Z. Very-low-birthweight breech infants: Short-term outcome by method of delivery. J Matern Fetal Med 1997;6(3):155-8.

8. Dessardo N, Mustać E, Dessardo S, Banac S, Peter B, Finderle A, et al. Chorioamnionitis and chronic lung disease of prematurity: a path analysis of causality. Am J Perinatol. 2011Jun;29(02):133-40.

9. Saadat M, Nejad SM, Habibi G, Sheikhvatan M. Maternal and neonatal outcomes in women with preeclampsia. Taiwan J Obstet Gynecol 2007;46(3):255-9.

10. Network TIN. The CRIB (clinical risk index for babies) score: a tool for assessing initial neonatal risk and comparing performance of neonatal intensive care units. Lancet1993;342(8865):193-8.

11. Papile LA, Munsick-Bruno G, Schaefer A. Relationship of cerebral intraventricular hemorrhage and early childhood neurologic handicaps. J Pediatr 1983;103:273-7.

12. Bell MJ, Ternberg JL, Feigin RD, Keating JP, Marshall R, Barton L, et al. Neonatal necrotizing enterocolitis. Therapeutic decisions based upon clinical staging. Ann Surg 1978;187: 1-7.

13. Ricci Z, Ronco C. Neonatal RIFLE. Nephrol Dial Transplant 2013 Sep;28(9):2211-4.

14. Vries LSD, Eken P, Dubowitz LM. The spectrum of leukomalacia using cranial ultrasound. Behav Brain Res 1992;49(1):1-6.

15. Jobe AH, Bancalari E. Bronchopulmonary dysplasia. Am J Respir Crit Care Med 2001 Jun;163(7):1723-9

16. Malloy MH. Impact of cesarean section on neonatal mortality rates among very preterm infants in the United States, $2000-2003$. Pediatrics 2008Jan;122(2):285-92.

17. Deulofeut R, Sola A, Rogido M. The impact of vaginal delivery in premature infants weighing less than 1,251 grams. Obstet Gynecol 2005;106(3):641-2.

18. Westgren M, Dolfin T, Halperin M, Milligan J, Shennan A, Svenningsen NW, et al. Mode of delivery in the low birth weight fetus. delivery by cesarean section independent of fetal lie versus vaginal delivery in vertex presentation. Acta Obstet Gynecol Scand 1985;64(1):51-7.

19. Malloy MH. Increasing cesarean section rates in very low—birth weight infants. JAMA1989;262(11):1475.

20. Grandi C, González A, Zubizarreta J, NEOCOSUR Neonatal Network. Perinatal factors associated with neonatal mortality in very low birth weight infants: a multicenter study. Arch Argent Pediatr 2016;114(5):426-33.

21. Barber CA, Sikes NC, Norton JD, Lowery CL, Sponsor K. Effects of mode of delivery on mortality and severe brain injury in extremely low birth weight infants. J Ark Med Soc 2007;104(3):63-6.

22. Zhu J-J, Bao Y-Y, Zhang G-L, Ma L-X, Wu M-Y. No relationship between mode of delivery and neonatal mortality and neurodevelopment in very low birth weight infants aged two years. World J Pediatr 2014;10(3):227-31.

23. Takahashi H, Watanabe N, Sugibayashi R, Aoki H, Egawa M, Sasaki A, et al. Increased rate of cesarean section in primiparous women aged 40 years or more: a single-center study in Japan. Arch Gynecol Obstet 2011May;285(4):937-41.

24. Riskin A, Riskin-Mashiah S, Lusky A, Reichman B; Israel Neonatal Network. The relationship between delivery mode and mortality in very low birthweight singleton vertex-presenting infants. BJOG 2004;111:1365-71

25. Riskin A, Riskin-Mashiah S, Bader D, Kugelman A, Lerner-Geva L, Boyko V, et al. Delivery mode and severe intraventricular hemorrhage in single, very low birth weight, vertex infants. Obstet Gynecol 2008;112(1):21-8.

26. Westgren M, Dolfin T, Halperin M, Milligan J, Shennan A, Svenningsen NW, et al. Mode of delivery in the low birth weight fetus: delivery by cesarean section independent of fetal lie versus vaginal delivery in vertex presentation-a study with long-term followup. Acta Obstet Gynecol Scand 1985;64(1):51-7.

27. Jonas HA, Khalid N, Schwartz SM. The relationship between Cesarean section and neonatal mortality in very-low-birthweight infants. Paediatr Perinat Epidemiol 1999;13:170-89.

28. Jonas HA, Lumley JM. The effect of mode of delivery on neonatal mortality in very low birthweight infants born in Victoria, Australia: caesarean section is associated with increased survival in breechpresenting, but not vertex-presenting, infants. Paediatr Perinat Epidemiol 1997;11:181- 99. 